\title{
Mycobacterium palustre sp. nov., a potentially pathogenic, slowly growing mycobacterium isolated from clinical and veterinary specimens and from Finnish stream waters
}

\footnotetext{
1 Laboratory of Environmental Microbiology, National Public Health Institute, PO Box 95, FIN-70701 Kuopio, Finland

2 Department of Clinical Microbiology, Kuopio University Hospital, PO Box 1777, FIN-70211 Kuopio, Finland

${ }^{3}$ Institute of Biotechnology, University of Helsinki, PO Box 56, FIN-00014 Helsinki University, Finland

${ }^{4}$ Regional Mycobacteria Reference Centre, Bacteriological and Virological Laboratory, Careggi Hospital, Viale Morgagni 85, I-50134 Florence, Italy

${ }^{5}$ Department of Bacteriology, National Veterinary and Food Research Institute, PO Box 45, FIN-00581 Helsinki, Finland
}

\author{
Pirjo Torkko, ${ }^{1,2}$ Sini Suomalainen, ${ }^{3} \dagger$ Eila livanainen, ${ }^{1}$ Enrico Tortoli, ${ }^{4}$ \\ Merja Suutari, ${ }^{1}$ Jaana Seppänen, ${ }^{5}$ Lars Paulin $^{3}$ and Marja-Leena Katila ${ }^{2}$
}

Author for correspondence: Pirjo Torkko. Tel: +358 17201 211. Fax: +358 17201155 . e-mail: pirjo.torkko@ktl.fi

Taxonomic studies were performed on a phenotypically homogeneous group of 13 mycobacteria isolated from clinical, veterinary and stream-water samples. The methods applied included chromatographic analyses of bacterial lipids, biochemical tests and sequencing of the 16S rDNA and the internal transcribed spacer 1 (ITS1) region. Positive results in urease, Tween 80 hydrolysis and pyrazinamidase tests and a negative result in a semiquantitative catalase test, combined with the ability to grow at $42{ }^{\circ} \mathrm{C}$, distinguished this group among the yellow-pigmented, slowly growing mycobacteria. Unique fatty acid and mycolic acid profiles in chromatographic analyses and the results of gene sequencing indicated that the novel isolates represent a previously undescribed species, for which the name Mycobacterium palustre sp. nov. is proposed. The fatty acid profile obtained by GLC was characterized by the presence of several methyl-branched fatty acid markers. The most prominent markers were 2-methyleicosanoic, tetracosanoic and hexacosanoic acids. According to 165 rDNA sequencing, M. palustre is phylogenetically closest to Mycobacterium kubicae, a recently described species. M. palustre gives a false-positive result in a hybridization test with the AccuProbe Mycobacterium avium complex. One of the strains was isolated from a lymph-node biopsy from a child with cervical lymphadenitis. Thus, M. palustre should be listed among potential inducers of paediatric lymphadenitis. The veterinary isolates originated from the lymph nodes of slaughter pigs. The majority of the strains were recovered from natural waters, which highlights the role of the environment as a source of potentially pathogenic mycobacteria. The type strain of $M$. palustre is strain E846 ${ }^{\top}$ (= DSM $\mathbf{4 4 5 7 2}^{\top}=$ ATCC $^{\text {BAA-377' }}$ ).

Keywords: Mycobacterium palustre sp. nov., identification, taxonomy, GLC, HPLC

\section{INTRODUCTION}

In an environmental study on mycobacteria in Finnish stream waters (Iivanainen et al., 1993), we recovered eight isolates with a unique combination of phenotypic

† Present address: deCODE Cancer, Krókháls 5, IS-110 Reykjavik, Iceland. Abbreviations: ITS1, internal transcribed spacer 1; MACP, mycolic acid cleavage product.

The GenBank accession number for the 16S rRNA gene and ITS1 region sequence of strain E846 ${ }^{\top}$ is AJ308603. properties, including identical GLC profiles of fatty acids and mycolic acid cleavage products (MACPs). Similar GLC profiles were also recognized among our collections of clinical and veterinary isolates that had remained without definite species identification. These comprised four isolates from Finland and one from Italy (Tortoli et al., 1997). The polyphasic characterization of these isolates is reported in this paper. The isolates formed a distinct group most closely related to a recently described species, Mycobacterium kubicae (Floyd et al., 2000). Several genetic and 
chemotaxonomic differences distinguished this group from all known mycobacterial species, including $M$. kubicae. On the basis of the results described, this group of 13 isolates is considered to represent a novel species of the genus Mycobacterium, for which we propose the name Mycobacterium palustre sp. nov.

\section{METHODS}

Bacterial strains. Thirteen isolates were included in the study. Eight isolates (E58, E168, E171, E340, E520C, E712, E832 and $E 846^{\mathrm{T}}$ ) were cultured from water samples from four Finnish streams, as described previously in detail (Iivanainen et al., 1993). They were recovered after decontamination with $2 \mathrm{M} \mathrm{H}_{2} \mathrm{SO}_{4}+$ cycloheximide. No similar colonies were detected after decontamination with $4 \% \mathrm{NaOH}$ and $5 \%$ oxalic acid (Iivanainen et al., 1993). Six of the eight isolates were recovered in egg-based media at $\mathrm{pH} 5 \cdot 5$. Two Finnish clinical isolates (HO 036/91 and 3739-1/99) were grown from sputum specimens, one of them exclusively in the MGIT 960 system (BD Biosciences) in the primary isolation (Katila et al., 2000). An Italian clinical strain (Fi-16795) was recovered from a lymph-node biopsy from a 4-year-old girl with swelling in the right submandibular region. She presented with a slightly aching lymph node. The infection progressed rapidly, manifesting as colliquation of the lymph node within a week, and the appearance of another one. Her tuberculin skin test (Mantoux) was positive but, otherwise, haematological and other clinical laboratory findings were within the normal range. Microscopy of the biopsy specimen of the lymph node revealed acid-fast bacilli, and the culture grew mycobacteria in both solid and liquid media (Bactec 12B; Becton Dickinson) at 4 and 2 weeks, respectively. Despite treatment with various antibiotics, also including isoniazid and rifampicin at a later stage, the lesion fistulated, secreting a yellowish, purulent discharge. The lymph node conglomerate was removed surgically and the child recovered without relapse. Two Finnish veterinary isolates (629 and 4942) were grown from specimens of submandibular lymph nodes from finishing pigs sampled at a normal meat inspection in a slaughterhouse in 1996. The reference strains used in this study were Mycobacterium interjectum ATCC $51457^{\mathrm{T}}$ and Mycobacterium intermedium DSM $44049^{\mathrm{T}}$ for GLC analyses and Mycobacterium intracellulare ATCC $13950^{\mathrm{T}}$ and $M$. kubicae ATCC $700732^{\mathrm{T}}$ for HPLC analyses.

Lipid analyses. For the present study, all isolates were grown on Middlebrook 7H11 agar (Difco). GLC of fatty acids, fatty alcohols and MACPs was performed as described previously in detail (Torkko et al., 1998). For identification of fatty acid methyl esters and MACPs, GLC-MS analyses were performed as described previously (Torkko et al., 1998). Trimethylsilyl derivatives of alcohols were prepared as described elsewhere (Torkko et al., 1998) and double bonds were hydrated using a method published previously (Suutari \& Laakso, 1993).

Mycolic acids were saponified and extracted from whole cells and derivatized to bromophenacyl esters as reported previously (Butler et al., 1992; Tortoli \& Bartoloni, 1996). HPLC was performed using a reverse-phase $\mathrm{C}_{18}$ Ultrasphere-XL cartridge column (Beckman) on an HPLC instrument (System Gold model; Beckman).

Conventional tests. The isolates were investigated for the following properties, as described previously (Torkko et al., 1998, 2000): nitrate reduction, production of arylsulfatase
(10 days), pyrazinamidase, semi-quantitative catalase and urease and hydrolysis of Tween 80 . The production of alkaline phosphatase, acid phosphatase, $\alpha$-galactosidase and $\beta$-galactosidase was determined using the API ZYM system (bioMérieux) as recommended by the manufacturer, but using overnight incubation at $36^{\circ} \mathrm{C}$ as reported by Tortoli et al. (1996). Testing for the temperature range for growth was performed on egg-based media (Vincent Lévy-Frébault \& Portaels, 1992).

All isolates were tested with a commercial DNA probe (AccuProbe; GenProbe) specific for the Mycobacterium avium complex and for the species $M$. avium and $M$. intracellulare. Furthermore, five isolates were also tested with another commercial probe system (INNO LiPA MYCOBACTERIUM; Innogenetics). In both cases, the instructions of the manufacturers were followed.

$16 S$ rDNA sequencing and phylogenetic analysis. Amplification of the complete $16 \mathrm{~S}$ rRNA gene and sequencing of the amplified DNA fragments of isolates E171, E520C, E712 and $\mathrm{E} 846^{\mathrm{T}}$ were performed as described previously (KoukilaKähkölä et al., 1995). The other isolates were sequenced, the hypervariable regions A and B of the 16S rRNA gene being partially covered. A phylogenetic tree was constructed by using methods described in detail previously (Torkko et al., 2000).

Internal transcribed spacer (ITS) region sequencing. All isolates were amplified and the amplification products were sequenced for the ITS1 region between the $16 \mathrm{~S}$ and $23 \mathrm{~S}$ rDNAs as described in detail previously (Torkko et al., 2000).

Environmental analyses. Characteristics of the drainage areas and the chemical, physical and microbiological quality of the natural water reservoirs of the environmental isolates in the target group were analysed as described in detail previously (Iivanainen et al., 1993).

\section{RESULTS AND DISCUSSION}

\section{Lipid analyses}

GLC fatty acid analysis of the novel isolates revealed a unique pattern. In addition to fatty acids regarded as typical of mycobacteria (Jantzen et al., 1989), four different methyl-branched fatty acids were detected. These included 2-methyleicosanoic acid (2-Me-20:0), which was the most prominent, 2-methyldecanoic acid (2-Me-10:0), 2-methylnonadecanoic acid (2-Me-19:0) and 2,9-dimethyleicosanoic acid (2,9-diMe-20:0) (Fig. 1). Additional minor, but constant, markers, which could be used in separation of this species, included 14-phenyltetradecanoate (14-phe-14:0) and 2-methyl16-phenylhexadecanoate (2-Me-16-phe-16:0), respectively with mass ions at $m / z 318$ and 360 and relative retention times of 1.81 and 2.04 (tetradecanoate $=$ $1 \cdot 0)$. The mass spectra of these previously undescribed compounds among the MACPs contained ions $m / z 91$ and 104 , respectively originating from fragments phenyl- $\mathrm{CH}_{2}-$ and phenyl- $\mathrm{CH}_{2}-\mathrm{CH}-$. Phenyl groups have previously been found as structural components of mycobacteria, though unrelated to MACPs (Brennan \& Nikaido, 1995; Barry et al., 1998). In addition, the compound 2-methyl-16-phenylhexadecanoate contained fragments $m / z 88$ and 101, 


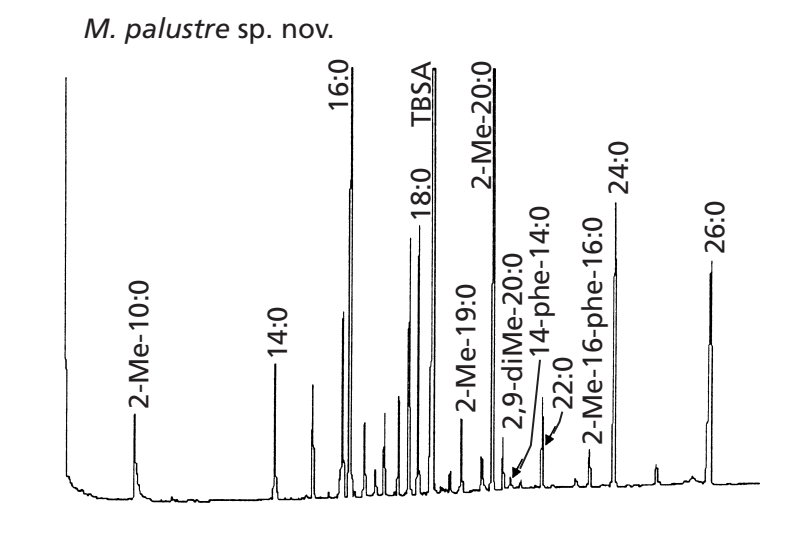

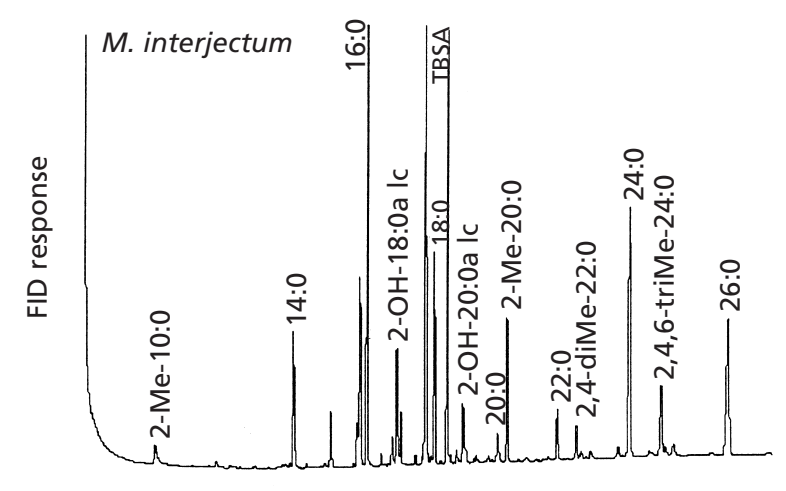

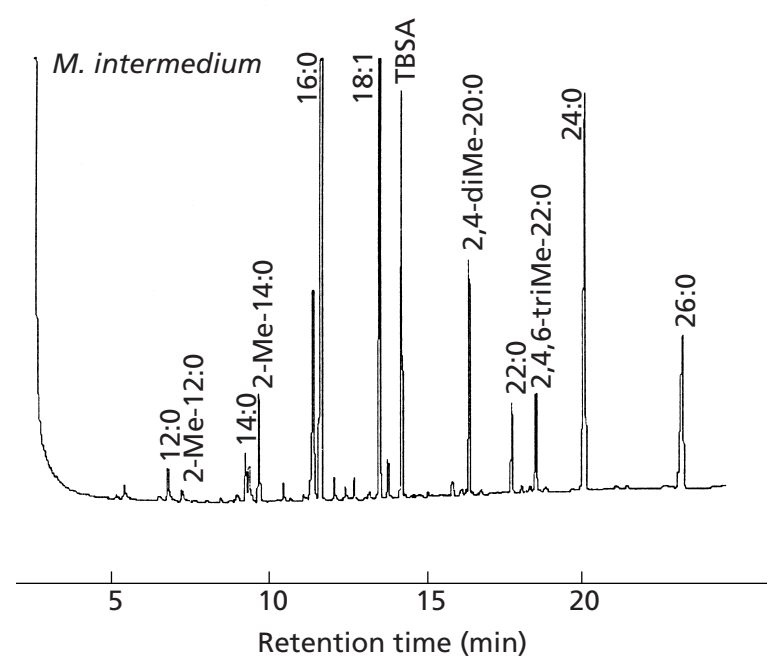

Fig. 1. GLC profiles of $M$. palustre sp. nov., $M$. interjectum and $M$. intermedium. For definitions of marker designations, see Results and Discussion. FID, Flame ionization detector; TBSA, tuberculostearic acid.

known to be typical fragments of 2-methyl-branched fatty acid methyl esters (Julák et al., 1980). In addition to these branched-chain fatty acids, both tetracosanoic (24:0) and hexacosanoic acids (26:0) were present.

Fig. 1 presents the GLC profiles of strain E846 ${ }^{\mathrm{T}}$ and two other yellow-pigmented mycobacteria, $M$. intermedium and $M$. interjectum, which biochemically resemble the group of strains studied. In addition to

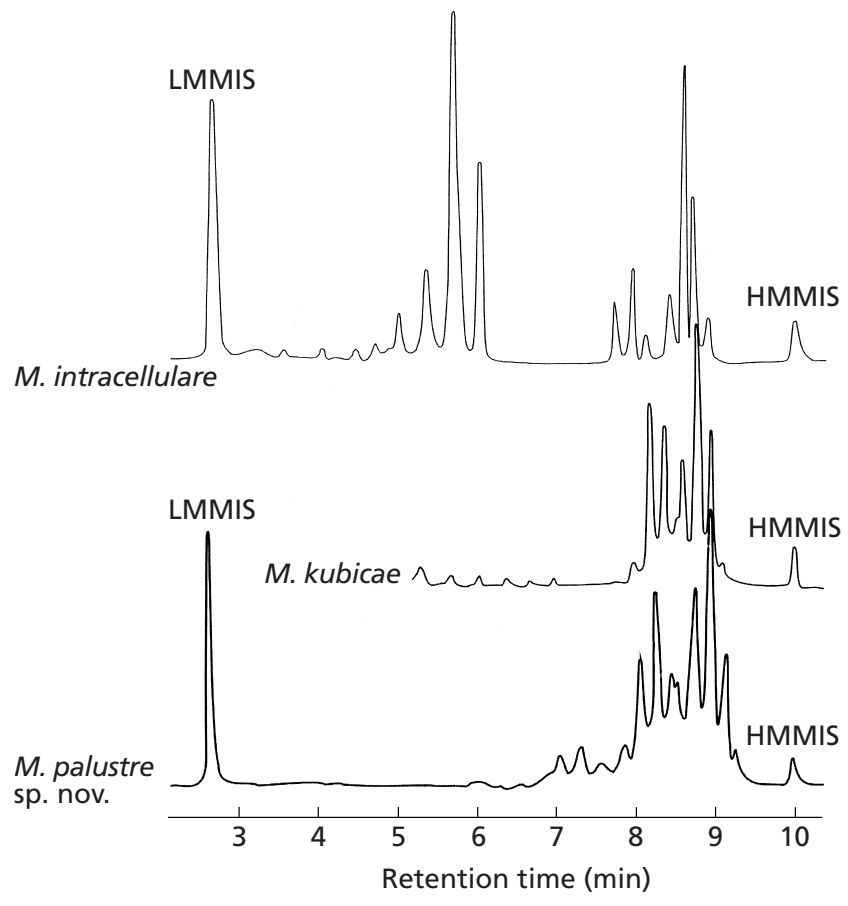

Fig. 2. Mycolic acid patterns of $M$. palustre sp. nov., $M$. intracellulare and $M$. kubicae obtained by HPLC analyses. LMMIS, Low-molecular-mass internal standard; HMMIS, highmolecular-mass internal standard.

containing MACPs 24:0 and 26:0, these two mycobacterial species are also rich in methyl-branched fatty acids. However, each of these three species has a unique pattern of branched-chain fatty acid markers, which enables their separation on the basis of GLC profiles.

In HPLC analysis of mycolic acids, the profile of the isolates studied showed a single cluster of peaks similar to that present in Mycobacterium asiaticum and M. kubicae (Floyd et al., 2000) (Fig. 2). However, differences in peak-heights and the presence of an additional late-emerging peak allowed their differentiation.

\section{5 rDNA and ITS region sequencing and phylogenetic analysis}

The 13 pigmented isolates comprising the group studied had identical 16S rDNA and ITS1 region sequences (Fig. 3). A similar 16S rDNA sequence, from an unidentified, non-pigmented isolate, was previously submitted to GenBank (Mycobacterium sp. IWGMT 90210; Wayne et al., 1996). A difference of two nucleotides was detected between this sequence and the 16S rDNA of our isolates. Strain IWGMT 90210 differed from the novel isolates in the absence of pigment production and growth at $45^{\circ} \mathrm{C}$ (Wayne et $a l ., 1996)$. This isolate was unavailable for comparative analyses. 

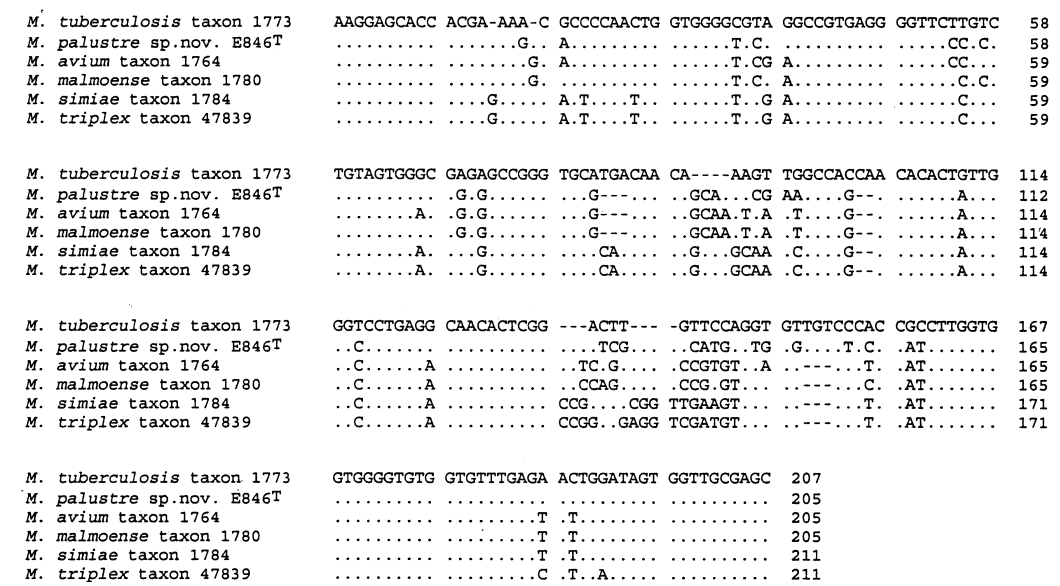

\section{205
205
205
211}

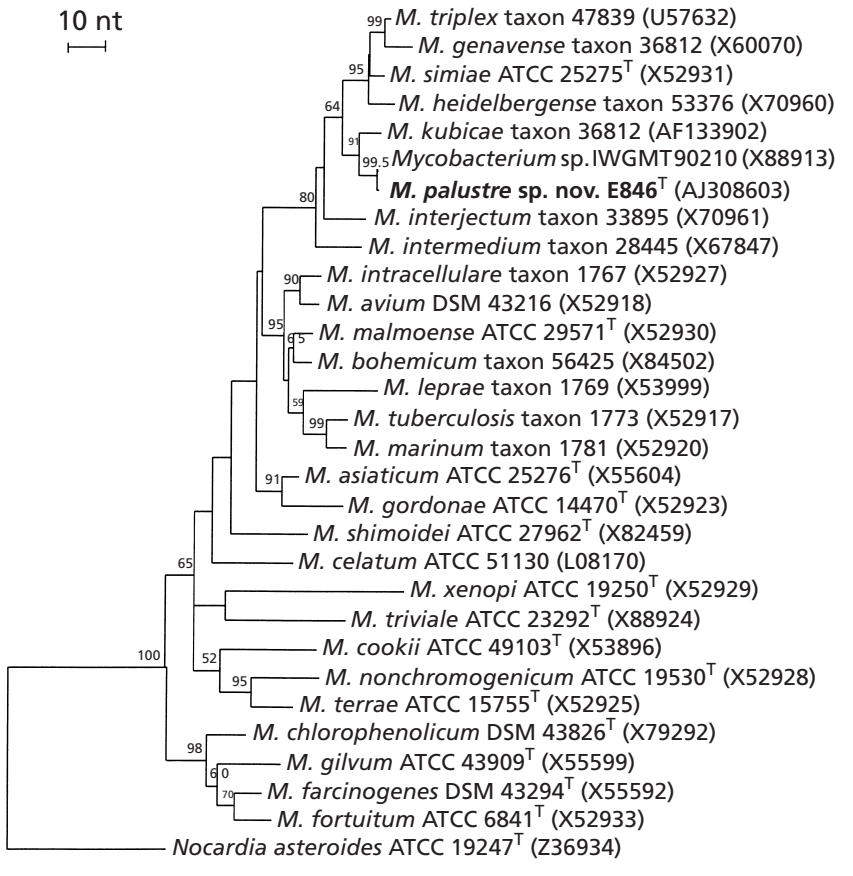

Fig. 4. Phylogenetic tree based on 165 rDNA sequences showing the relationships of $M$. palustre sp. nov. and selected Mycobacterium species. This tree was constructed using the neighbour-joining method. The tree was rooted by using Nocardia asteroides as the outgroup. Sequence accession numbers are given in parentheses. Bar, 10 nt difference.

In a phylogenetic tree (Fig. 4) based on evaluation of $16 \mathrm{~S}$ rDNA sequences, the novel group is located among the slowly growing mycobacteria, being most closely related to M. kubicae.

\section{Cultural, biochemical and hybridization properties}

Colonies were smooth and yellow to pale yellow. Isolates grew as scotochromogenic colonies at $36^{\circ} \mathrm{C}$, but 11 of 13 were photochromogenic at $42^{\circ} \mathrm{C}$. Mature colonies were observed on egg media from dilute inocula after 4-5 weeks incubation at the optimum temperature of $36{ }^{\circ} \mathrm{C}$. Colonies were larger on Middlebrook agar than on egg-based media, and reached a colony size of $1-1.5 \mathrm{~mm}$ in diameter in 4 weeks. The results of biochemical testing of the examined group and three other slowly growing species, all of which grow at $42{ }^{\circ} \mathrm{C}$, are presented in Table 1 .

All clinical, veterinary and environmental isolates hybridized with $M$. avium complex AccuProbe but not with the species-specific probes for $M$. avium and $M$. intracellulare. In contrast, no hybridization was obtained with LiPA DNA probes, either with the probe for the $M$. avium-intracellulare-scrofulaceum group or with any of the probes specific for single species (Tortoli et al., 2001). The different genomic regions involved in these tests could explain this difference: AccuProbe is based on the 16S rDNA and LiPA on the ITS region.

\section{Environmental data}

Natural water, especially in peaty regions, appears to be a rich source of mycobacteria in Finland (Iivanainen et al., 1993). Such water was also found to be a possible reservoir of the newly described potential pathogen, which was isolated from four of the 53 streams analysed in our initial environmental survey. The sampling sites were located within a distance of approx. $350 \mathrm{~km}$. The four water samples were acidic (between pH 5.6 and 5.9). Seven of the eight isolates were recovered from three drainage areas widely covered by peatlands $(60-75 \%$ of the area). These water samples were rich in mycobacteria (8002200 c.f.u. $1^{-1}$ ) and all had a high content of organic matter, as indicated by chemical oxygen demands of $80-140 \mathrm{mg} \mathrm{KMnO}_{4} \mathrm{1}^{-1}$ and colour values of 160 $600 \mathrm{mg} \mathrm{Pt} \mathrm{l}^{-1}$. In contrast, one isolate was recovered from a drainage area with $20 \%$ peatland coverage. This water also had lower contents of organic matter (chemical oxygen demand of $65 \mathrm{mg} \mathrm{KMnO}_{4} \mathrm{l}^{-1}$ and colour value of $180 \mathrm{mg} \mathrm{Pt} \mathrm{l}^{-1}$ ) and mycobacteria $\left(320\right.$ c.f.u. $\left.1^{-1}\right)$. 
Table 1. Comparison of cultural and biochemical characteristics that help in the differentiation of $M$. palustre sp. nov., M. avium, M. xenopi and $M$. bohemicum

Values are percentages of strains that tested positive. Data for $M$. avium and $M$. xenopi were taken from Wayne et al. (1991). Data for M. bohemicum were modified from Torkko et al. (2001). Growth of $M$. bohemicum at $22{ }^{\circ} \mathrm{C}$ was calculated from the results for the five environmental isolates in that study. ND, Not determined.

\begin{tabular}{|lcccc|}
\hline Characteristic & M. palustre & M. avium & M. xenopi & M. bohemicum \\
\hline Pigmentation & Yellow & None* & Yellow & Yellow \\
Scotochromogenic & $100 \dagger$ & 8 & 86 & 100 \\
Photochromogenic & $85 \dagger$ & 1 & 1 & 0 \\
Tween 80 hydrolysis & 100 & 1 & 1 & 20 \\
Semi-quantitative catalase & 0 & 8 & 1 & 100 \\
(45 mm foam) & & & & \\
Urease & 100 & 1 & 1 & 93 \\
Arylsulfatase (10 days) & 46 & 29 & 99 & 87 \\
Nitrate reduction & 54 & 1 & 1 & 60 \\
Pyrazinamidase & 100 & 50 & 50 & 27 \\
Acid phosphatase & 100 & 1 & 1 & ND \\
Alkaline phosphatase & 85 & ND & ND & ND \\
$\alpha$-Galactosidase & 0 & ND & ND & ND \\
$\beta$-Galactosidase & 0 & 1 & 1 & ND \\
Growth at: & & & & 60 \\
$22^{\circ} \mathrm{C}$ & 0 & $99 \ddagger$ & $1+$ & 00 \\
$42^{\circ} \mathrm{C}$ & $23 \S$ & 50 & 99 & 0 \\
$45^{\circ} \mathrm{C}$ & & &
\end{tabular}

* Usually non-pigmented, but may develop yellow pigment.

$\dagger$ Scotochromogenic at $36^{\circ} \mathrm{C} ; 85 \%$ of isolates photochromogenic at $42{ }^{\circ} \mathrm{C}$.

$\ddagger$ Results for growth at $25^{\circ} \mathrm{C}$.

$\S$ All isolates grew from heavy inocula on Middlebrook agar at $45^{\circ} \mathrm{C}$ in 6 weeks.

\section{Clinical significance of human and veterinary isolates}

One of the clinical isolates was regarded as an unquestionable inducer of mycobacterial lymphadenitis in an Italian child. Thus, the proposed novel species should be included among potential inducers of paediatric cervical lymphadenitis (Wolinsky, 1995; Springer et al., 1993; Tortoli et al., 1999, 2000). On the basis of the available information, the clinical significance of the other clinical strains could not be verified. One was co-isolated with Mycobacterium bohemicum from a single sputum specimen from an elderly patient; the other was isolated from another elderly patient, lost to follow-up.

Known veterinary mycobacterial pathogens, such as the $M$. avium complex and Mycobacterium xenopi, prefer higher temperatures for growth than most nonpathogenic species. The broad range of growth temperatures of the isolates studied may indicate enhanced ability to colonize warm-blooded animals such as pigs. In our cases, these veterinary isolates were recovered from abnormal lymph nodes taken at meat inspections of otherwise healthy slaughter pigs. During the short lifetime of slaughter pigs, infections due to slowly growing mycobacteria are not likely to be manifested as more severe disease forms. Thus, the role of this novel species as an inducer of true porcine disease remains to be evaluated.

An interesting co-isolation with $M$. bohemicum, another recently described species (Reischl et al., 1998), occurred not only from one clinical specimen but also from one environmental sample (E846 ${ }^{\mathrm{T}}$; formerly numbered E170 and E170-1) (Torkko et al., 2001). These two rare, yellow-pigmented species differ in colony appearance, and they can be separated easily by fatty acid, mycolic acid or biochemical analyses.

\section{Differentiation of M. palustre sp. nov. from other slowly growing, pigmented mycobacteria}

$M$. palustre sp. nov. is a yellow-pigmented species that hydrolyses Tween 80 , splits urea and produces less than $45 \mathrm{~mm}$ foam in the semi-quantitative catalase test. It grows at temperatures in the range $30-42{ }^{\circ} \mathrm{C}$. This pattern of test results is unique among pigmented, slowly growing mycobacteria. Other pigmented, slowly growing mycobacteria that grow at $42^{\circ} \mathrm{C}$ include the three related species M. xenopi, Mycobacterium botniense (Torkko et al., 2000) and Mycobacterium heckeshornense (Roth et al., 2000) and most 
isolates of M. avium and Mycobacterium celatum. Both $M$. avium and $M$. celatum may vary in pigment production. An important characteristic of $M$. palustre is its confusing hybridization with the $M$. aviumcomplex AccuProbe. However, if two simple conventional tests, urease and Tween 80 hydrolysis, are included in the species verification, $M$. palustre is easily separated even from yellow-pigmented isolates of the $M$. avium complex, M. xenopi and $M$. celatum.

In GLC analyses, $M$. palustre is characterized by the presence of notable amounts of 2-Me-20:0, 24:0 and $26: 0$ in addition to minor amounts of $2-\mathrm{Me}-19: 0,2,9-$ diMe-20:0, 14-phe-14:0 and 2-Me-16-phe-16:0. $M$. avium, $M$. xenopi and $M$. celatum are devoid of these methyl-branched fatty acids. In all, a combination of 26:0 and methyl-branched fatty acids other than tuberculostearic acid (10-Me-18:0) is uncommon. It is a characteristic of $M$. interjectum and $M$. intermedium (in addition to M. palustre) (Fig. 1). Among these two species, $M$. interjectum typically contains the secondary alcohols 2-octadecanol (2-OH-18:0alc) and 2-eicosanol (2-OH-20:0alc) and $M$. intermedium is characterized by a fatty acid pattern containing a combination of 2-methyldodecanoic acid (2-Me12:0), 2-methyltetradecanoic acid (2-Me-14:0), 2,4dimethyleicosanoic (2,4-diMe-20:0) and 2,4,6trimethyldocosanoic acid (2,4,6-triMe-22:0). The HPLC profile of mycolic acid bromophenacyl esters of $M$. palustre is similar, but not identical, to that of $M$. kubicae. These two recently described species can be further separated by biochemical and growth characteristics.

\section{Description of Mycobacterium palustre sp. nov.}

Mycobacterium palustre (pa'lus.tre. L. adj. palustre living in swamps, referring to the isolation of most members of this novel species from peatland run-off water).

Cells are acid- and alcohol-fast bacilli. Visible growth from a dilute inoculum requires $2-3$ weeks. Mature colony size is reached in 4 weeks at $36^{\circ} \mathrm{C}$. Growth occurs at temperatures between 30 and $42{ }^{\circ} \mathrm{C}, 36^{\circ} \mathrm{C}$ being regarded as the optimum temperature. Growth at $45^{\circ} \mathrm{C}$ is detected from a heavy inoculum on Middlebrook agar after 5-6 weeks. Colonies on eggbased media and Middlebrook agar are smooth, scotochromogenic at $36^{\circ} \mathrm{C}$ and photochromogenic or scotochromogenic at $42^{\circ} \mathrm{C}$. The species yields positive results in urease, pyrazinamidase, acid phosphatase and Tween 80 hydrolysis tests and variable results in nitrate reduction and alkaline phosphatase tests. Test results are negative for semi-quantitative catalase (45 $\mathrm{mm}$ foam), $\alpha$-galactosidase and $\beta$-galactosidase. In GLC analyses, $M$. palustre is characterized by the presence of notable amounts of 2-Me-20:0, 24:0 and $26: 0$ in addition to minor amounts of $2-\mathrm{Me}-10: 0,2-$ Me-19:0, 2,9-diMe-20:0, 14-phe-14:0 and 2-Me-16phe-16:0. Phylogenetic analysis, based on 16S rDNA sequences, places $M$. palustre among the slowly growing mycobacteria, being most closely related to M. kubicae.

The type strain is strain $\mathrm{E} 846^{\mathrm{T}}$ ( = ATCC BAA-377 $=\mathrm{DSM} 44572^{\mathrm{T}}$ ), isolated from water from a stream in Finland. A veterinary isolate (strain 629) has also been deposited in the DSMZ, as DSM 44571.

\section{ACKNOWLEDGEMENTS}

We thank the Environment, Health and Society programme of the University of Kuopio, and the Finnish Lung Health Association for financial support. We also express our gratitude to Laila Ahola, BA, for help with nomenclature, Lea Olkkonen, MSc, and Professor Eeva-Liisa Hintikka for providing us with clinical and veterinary isolates.

\section{REFERENCES}

Barry, C. E., III, Lee, R. E., Mdluli, K., Sampson, A. E., Schroeder, B. G., Slayden, R. A. \& Yuan, Y. (1998). Mycolic acids: structure, biosynthesis and physiological functions. Prog Lipid Res 37, 143-179.

Brennan, P. J. \& Nikaido, H. (1995). The envelope of mycobacteria. Annu Rev Biochem 64, 29-63.

Butler, W. R., Thibert, L. \& Kilburn, J. O. (1992). Identification of Mycobacterium avium complex strains and some similar species by highperformance liquid chromatography. J Clin Microbiol 30, 2698-2704.

Floyd, M. M., Gross, W. M., Bonato, D. A., Silcox, V. A., Smithwick, R. W., Metchock, B., Crawford, J. T. \& Butler, W. R. (2000). Mycobacterium kubicae sp. nov., a slowly growing, scotochromogenic Mycobacterium. Int J Syst Evol Microbiol 50, 1811-1816.

livanainen, E. K., Martikainen, P. J., Väänänen, P. K. \& Katila, M.-L. (1993). Environmental factors affecting the occurrence of mycobacteria in brook waters. Appl Environ Microbiol 59, 398-404.

Jantzen, E., Tangen, T. \& Eng, J. (1989). Gas chromatography of mycobacterial fatty acids and alcohols: diagnostic applications. APMIS 97, 1037-1045

Julák, J., Tureček, F. \& Miková, Z. (1980). Identification of characteristic branched-chain fatty acids of Mycobacterium kansasii and gordonae by gas chromatography-mass spectrometry. J Chromatogr 90, $183-187$.

Katila, M.-L., Katila, P. \& Erkinjuntti-Pekkanen, R. (2000). Accelerated detection and identification of mycobacteria with MGIT 960 and COBAS AMPLICOR systems. J Clin Microbiol 38, 960-964.

Koukila-Kähkölä, P., Springer, B., Böttger, E. C., Paulin, L., Jantzen, E. \& Katila, M.-L. (1995). Mycobacterium branderi sp. nov., a new potential human pathogen. Int J Syst Bacteriol 45, 549-553.

Reischl, U., Emler, S., Horak, Z., Kaustova, J., Kroppenstedt, R. M., Lehn, N. \& Naumann, L. (1998). Mycobacterium bohemicum sp. nov., a new slow-growing scotochromogenic mycobacterium. Int J Syst Bacteriol 48, 1349-1355.

Roth, A., Reischl, U., Schönfeld, N., Naumann, L., Emler, S., Fischer, M., Mauch, H., Loddenkemper, R. \& Kroppenstedt, R. M. (2000). Mycobacterium heckeshornense sp. nov., a new pathogenic slowly growing Mycobacterium sp. causing cavitary lung disease in an immunocompetent patient. J Clin Microbiol 38, 4102-4107.

Springer, B., Kirschner, P., Rost-Meyer, G., Schröder, K.-H., Kroppenstedt, R. M. \& Böttger, E. C. (1993). Mycobacterium interjectum, a new species isolated from a patient with chronic lymphadenitis. J Clin Microbiol 31, 3083-3089.

Suutari, M. \& Laakso, S. (1993). Signature GLC-MS ions in identification of $\Delta^{5}$ - and $\Delta^{9}$-unsaturated iso- and anteiso-branched fatty acids. J Microbiol Methods 17, 39-48.

Torkko, P., Suutari, M., Suomalainen, S., Paulin, L., Larsson, L. \& Katila, M.-L. (1998). Separation among species of Mycobacterium terrae complex by lipid analyses: comparison with biochemical tests and 16S rRNA sequencing. $J$ Clin Microbiol 36, 499-505. 
Torkko, P., Suomalainen, S., livanainen, E., Suutari, M., Tortoli, E., Paulin, L. \& Katila, M.-L. (2000). Mycobacterium xenopi and related organisms isolated from stream waters in Finland and description of Mycobacterium botniense sp. nov. Int J Syst Evol Microbiol 50, 283-289.

Torkko, P., Suomalainen, S., livanainen, E. \& 7 other authors (2001). Characterization of Mycobacterium bohemicum isolated from human, veterinary, and environmental sources. J Clin Microbiol 39, 207-211.

Tortoli, E. \& Bartoloni, A. (1996). High performance liquid chromatography and identification of mycobacteria. Rev Med Microbiol 7, 207-219.

Tortoli, E., Bartoloni, A., Burrini, C., Colombrita, D., Mantella, A., Pinsi, G., Simonetti, M. T., Swierczynski, G. \& Böttger, E. C. (1996). Characterization of an isolate of the newly described species $\mathrm{Myco}$ bacterium interjectum. Zentbl Bakteriol 283, 286-294.

Tortoli, E., Piersimoni, C., Kirschner, P. \& 10 other authors (1997). Characterization of mycobacterial isolates phylogenetically related to, but different from Mycobacterium simiae. J Clin Microbiol 35, 697-702.

Tortoli, E., Kroppenstedt, R. M., Bartoloni, A., Caroli, G., Jan, I., Pawlowski, J. \& Emler, S. (1999). Mycobacterium tusciae sp. nov. Int J Syst Bacteriol 49, 1839-1844.
Tortoli, E., Bartoloni, A., Manfrin, V., Mantella, A., Scarparo, C. \& Böttger, E. (2000). Cervical lymphadenitis due to Mycobacterium bohemicum. Clin Infect Dis 30, 210-211.

Tortoli, E., Nanetti, A., Piersimoni, C. \& 11 other authors (2001). Performance assessment of new multiplex probe assay for identification of mycobacteria. J Clin Microbiol 39, 1079-1084.

Vincent Lévy-Frébault, V. \& Portaels, F. (1992). Proposed minimal standards for the genus Mycobacterium and for description of new slowly growing Mycobacterium species. Int J Syst Bacteriol 42, 315-323.

Wayne, L. G., Good, R. C., Krichevsky, M. I. \& 14 other authors (1991). Fourth report of the cooperative, open-ended study of slowly growing mycobacteria by the International Working Group on Mycobacterial Taxonomy. Int J Syst Bacteriol 41, 463-472.

Wayne, L. G., Good, R. C., Böttger, E. C. \& 19 other authors (1996). Semantide- and chemotaxonomy-based analyses of some problematic phenotypic clusters of slowly growing mycobacteria, a cooperative study of the International Working Group on Mycobacterial Taxonomy. Int J Syst Bacteriol 46, 280-297.

Wolinsky, E. (1995). Mycobacterial lymphadenitis in children: a prospective study of 105 nontuberculous cases with long-term followup. Clin Infect Dis 20, 954-963. 